Z Gerontol Geriat 2018 $51: 889-896$ https://doi.org/10.1007/s00391-017-1327-y Received: 17 December 2016 Revised: 28 May 2017

Accepted: 22 September 2017

Published online: 20 October 2017

(c) The Author(s) 2017. This article is an open access publication.

\section{CrossMark}

\author{
Peng Gao' · Qiwei Zhu' · Suyan Bian' • Hongwei Liu' · Hongping Xie \\ ' Department of Geriatric Cardiology, Chinese PLA General Hospital, Beijing, China \\ ${ }^{2}$ Department of Rehabilitation and Physiotherapy, First Affiliated Hospital of PLA General Hospital, Beijing, \\ China
}

\title{
Prognostic value of plasma NT-proBNP levels in very old patients with moderate renal insufficiency in China
}

events [7]. Stage $3 \mathrm{CKD}$ is classified as CKD3a if impairment of renal function is mild to moderate of CKD3b if impairment of renal function is moderate to severe. A decrease in renal function can be delayed and the risk of all-cause death and MACEs can be reduced if these patients receive comprehensive treatment; therefore, it is important to evaluate the risk of adverse events in patients with CKD stage 3. This study aimed to determine the prognostic value of NT-proBNP in very old ( $\geq 80$ years old) patients with CKD stage 3 and compare the prognostic value of NT-proBNP in CKD3a versus CKD3b.

\section{Methods}

\section{Study population}

This prospective observational study included very old (age $\geq 80$ years old) patients with stage $3 \mathrm{CKD}$ who were hospitalized in the Department of Geriatric Internal Medicine in the People's Liberation Army (PLA) General Hospital, Beijing, China. Patients with severe systemic diseases, such as collagenosis, inflammation, cachexia, severe liver disease, acute heart failure, or acute coronary syndrome, and those who had undergone coronary artery bypass grafting or percutaneous transluminal coronary angioplasty in the previous 6 months, were excluded. A total of 181 participants were eligible for the cross-sectional analysis from November 2007 to October 2010.
Follow-up visits were conducted in April 2015. The median follow-up interval for the original 181 patients was 3.8 years (interquartile range IQR 1.5-6.1). Of the patients 13 were lost to follow-up and were therefore excluded from the final analysis. Complete follow-up data were obtained from 168 patients (follow-up rate $92.8 \%$ ).

\section{Questionnaire and anthropometric measurements}

Information about patient age, smoking status, and history of coronary heart disease (CHD), diabetes mellitus (DM), hypertension, atrial fibrillation (AF), and tumors was collected by the physician on admission to the hospital. The physical examination included measurement of height and weight. After the patient had been in a sitting position for $\geq 5 \mathrm{~min}$, blood pressure was measured using a calibrated desktop sphygmomanometer (Yuyue, Armamentarium Limited Company, Jiangsu, People's Republic of China), consistent with current recommendations. Blood pressure was measured three times consecutively with $\geq 1$ min between measurements; the mean value was used for the statistical analysis.

Echocardiography was performed within 3 days after admission by an experienced echocardiography technician, who interpreted all scans. Left ventricular ejection fraction (LVEF) was determined using the biplane Simpson's 
Table 1 Baseline characteristics of patients included in this study

\begin{tabular}{|c|c|c|c|}
\hline \multirow{2}{*}{$\begin{array}{l}\text { Parameter } \\
\text { n }\end{array}$} & \multirow{2}{*}{$\begin{array}{l}\text { CKD3a } \\
117\end{array}$} & \multirow{2}{*}{$\begin{array}{l}\text { CKD3b } \\
51\end{array}$} & \multirow[t]{2}{*}{$p$-value } \\
\hline & & & \\
\hline Age (mean, years) & $87.4 \pm 2.7$ & $87.7 \pm 3.4$ & 0.626 \\
\hline $\mathrm{CHD}(\%)$ & $95(81.2 \%)$ & $44(86.2 \%)$ & 0.426 \\
\hline HT (\%) & 90 (76.9\%) & 49 (96.1\%) & 0.002 \\
\hline $\mathrm{AF}(\%)$ & $20(17.1 \%)$ & $8(15.7 \%)$ & 0.823 \\
\hline DM (\%) & 59 (50.4\%) & $29(56.9 \%)$ & 0.446 \\
\hline Tumor (\%) & $23(19.7 \%)$ & $7(13.7 \%)$ & 0.359 \\
\hline NT-proBNP (pg/mL) & $785.4 \pm 752.0$ & $1227.7 \pm 1177.8$ & 0.021 \\
\hline $\mathrm{eGFR}\left(\mathrm{ml} / \mathrm{min} / 1.73 \mathrm{~m}^{2}\right)$ & $53.7 \pm 4.0$ & $38.1 \pm 3.6$ & $<0.001$ \\
\hline $\mathrm{SCr}(\mu \mathrm{mol} / \mathrm{l})$ & $117.3 \pm 9.1$ & $157.3 \pm 16.8$ & $<0.001$ \\
\hline UN (mmol/l) & $9.0 \pm 2.0$ & $12.1 \pm 3.7$ & $<0.001$ \\
\hline $\mathrm{UA}(\mu \mathrm{mol} / \mathrm{l})$ & $372.3 \pm 79.6$ & $385.8 \pm 76.9$ & 0.428 \\
\hline $\mathrm{TC}(\mathrm{mmol} / \mathrm{l})$ & $4.1 \pm 0.6$ & $4.1 \pm 0.9$ & 0.771 \\
\hline LDL-C (mmol/l) & $2.3 \pm 0.5$ & $2.3 \pm 0.7$ & 0.861 \\
\hline $\mathrm{HDL}-\mathrm{C}(\mathrm{mmol} / \mathrm{l})$ & $1.1 \pm 0.2$ & $1.1 \pm 0.3$ & 0.565 \\
\hline TG $(\mathrm{mmol} / \mathrm{l})$ & $1.5 \pm 0.7$ & $1.6 \pm 0.5$ & 0.744 \\
\hline $\mathrm{Hb}(\mathrm{g} / \mathrm{l})$ & $122 \pm 13$ & $116 \pm 15$ & $p<0.001$ \\
\hline Plasma albumin (g/l) & $39.3 \pm 2.6$ & $38.8 \pm 2.5$ & 0.38 \\
\hline BMI & $24.0 \pm 2.4$ & $23.6 \pm 2.5$ & 0.449 \\
\hline mSBP $(\mathrm{mm} \mathrm{Hg})$ & $129.6 \pm 8.9$ & $128.7 \pm 9.0$ & 0.636 \\
\hline $\mathrm{mDBP}(\mathrm{mm} \mathrm{Hg})$ & $67.7 \pm 5.8$ & $66.5 \pm 5.7$ & 0.334 \\
\hline $\mathrm{MBP}(\mathrm{mm} \mathrm{Hg})$ & $88.3 \pm 6.0$ & $87.2 \pm 5.6$ & 0.379 \\
\hline $\mathrm{PP}(\mathrm{mm} \mathrm{Hg})$ & $62.0 \pm 8.3$ & $62.2 \pm 9.3$ & 0.885 \\
\hline LVEF (\%) & $59.5 \pm 4.0$ & $59.1 \pm 4.1$ & 0.686 \\
\hline $\mathrm{LAD}(\mathrm{mm})$ & $37.3 \pm 3.2$ & $37.6 \pm 3.2$ & 0.707 \\
\hline $\operatorname{LVMI}\left(\mathrm{g} / \mathrm{m}^{2}\right)$ & $127.7 \pm 22.0$ & $127.2 \pm 24.8$ & 0.918 \\
\hline Antiplatelet drugs (\%) & $80(68.4 \%)$ & 35 (68.6\%) & 0.974 \\
\hline Statin drugs (\%) & $50(42.7 \%)$ & $23(45.1 \%)$ & 0.778 \\
\hline CCB (\%) & $64(54.7 \%)$ & $29(56.9 \%)$ & 0.797 \\
\hline ACEI/ARB (\%) & $57(48.7 \%)$ & 27 (52.9\%) & 0.617 \\
\hline Beta-blocker (\%) & $40(34.2 \%)$ & $26(51.0 \%)$ & 0.041 \\
\hline \multicolumn{4}{|c|}{$\begin{array}{l}C H D \text { coronary heart disease, } H T \text { hypertension, } A F \text { atrial fibrillation, } D M \text { diabetes mellitus, } \\
N T \text {-proBNP N-terminal pro-brain natriuretic peptide, eGFR estimated glomerular filtration } \\
\text { rate, } S C r \text { serum creatinine, } U N \text { urea nitrogen, } U A \text { uric acid, } T C \text { total cholesterol, } L D L-C \text { low-density } \\
\text { lipoprotein cholesterol, } H D L-C \text { high-density lipoprotein cholesterol, } T G \text { triglyceride, } H b \text { hemoglobin, } \\
B M I \text { body mass index, } m S B P \text { mean systolic blood pressure, } m D B P \text { mean diastolic blood pressure, } \\
M B P \text { mean blood pressure, } P P \text { pulse pressure, } L V E F \text { left ventricular ejection fraction, } L A D \text { left atrial di- } \\
\text { ameter, } L V M I \text { left ventricular mass index, } C C B \text { calcium channel blocker, } A C E l \text { angiotensin-converting } \\
\text { enzyme inhibitor, } A R B \text { angiotensin receptor antagonist }\end{array}$} \\
\hline
\end{tabular}

rule from apical 4-chamber and 2-chamber images of the heart [8]. Left atrial diameter (LAD), left ventricular endsystolic diameter (LVESD), left ventricular end-diastolic diameter (LVEDD), interventricular septum and posterior wall thickness (PWT) were measured on three consecutive heart beats and the results were averaged.

\section{Laboratory tests}

All patients underwent a complete laboratory evaluation. Blood samples were collected from patients between 6 am and 8 am after overnight fasting ( $\geq 12 \mathrm{~h}$ ). Peripheral blood samples were obtained to measure the following parameters: total cholesterol (TC), triglycerides, low-den-
(HDL-C), serum creatinine ( $\mathrm{sCr}$ ), blood urea nitrogen (BUN) and NT-proBNP. Concentrations of SCr were determined by an enzymatic assay (Roche Diagnostics, Basel, Switzerland) on a Hitachi 7600 autoanalyzer (Hitachi, Tokyo, Japan). The NT-proBNP level was determined with an electrochemiluminescence immunoassay (Roche Diagnostics, Mannheim, Germany) using a Roche analyzer (Roche Diagnostics, Indianapolis, IN).

\section{Definition of variables}

We calculated the estimated glomerular filtration rate (eGFR) using the Chinese version of the modification of diet in renal disease equation as follows [9]: eGFR $\left(\mathrm{ml} / \mathrm{min} / 1.73 \mathrm{~m}^{2}\right)=175 \times$ standard creatinine $(\mathrm{mg} / \mathrm{dl})^{-1.234} \times$ age $(\text { years })^{-0.179} \times$ 0.79 (if female). The CKD was defined according to the clinical practice guidelines [10], and CKD3a and CKD3b were defined as eGFR $45-59 \mathrm{ml} / \mathrm{min} / 1.73 \mathrm{~m}^{2}$ and $30-44 \mathrm{ml} / \mathrm{min} / 1.73 \mathrm{~m}^{2}$, respectively. Body mass index (BMI) was defined as weight $(\mathrm{kg})$ divided by the square of the height $(\mathrm{cm})$. We calculated left ventricular mass $(\mathrm{LVM})$ as $\mathrm{LVM}=(0.8$ [1.04 (LVEDd + PWTd + SWTd [interventricular septal end diastolic thickness] $)^{3}$ $\left.\left.(\text { LVEDd })^{3}\right]\right)+0.6 \mathrm{~g}[8]$, body surface area $(\mathrm{BSA})$ as $\mathrm{BSA}=0.0061 \times$ height + $0.0124 \times$ weight $^{-0.0099}[11]$, and left ventricular mass index (LVMI) as LVMI = LVM/BSA. Hypertension was defined as (i) systolic blood pressure $\geq 140 \mathrm{~mm} \mathrm{Hg}$, (ii) diastolic blood pressure $\geq 90 \mathrm{~mm} \mathrm{Hg}$ and/or (iii) use of an antihypertensive drug. Diabetes mellitus was indicated by the use of a hypoglycemic drug or insulin [12]. The diagnoses of CHD, AF, and tumors were confirmed by medical history. sity lipoprotein cholesterol (LDL-C), high-density lipoprotein cholesterol

\section{Follow-up}

Each patient medical record was reviewed by physicians every year of the baseline assessment. The major endpoints were all-cause death and MACEs. Death was ascertained from the death certificate, a legal document that includes time, place, and other information. The MACEs included nonfatal myocardial 
Z Gerontol Geriat 2018·51:889-896 https://doi.org/10.1007/s00391-017-1327-y

(c) The Author(s) 2017. This article is an open access publication.

P. Gao $\cdot$ Q. Zhu $\cdot$ S. Bian $\cdot$ H. Liu $\cdot$ H. Xie

\section{Prognostic value of plasma NT-proBNP levels in very old patients with moderate renal insufficiency in China}

Abstract

Background. The N-terminal pro-brain natriuretic peptide (NT-proBNP) has an important prognostic value in chronic renal insufficiency; however, most studies have been conducted in patients with endstage renal disease (ESRD). In this study we evaluated the prognostic significance of NTproBNP in very old patients with stage 3 chronic kidney disease (CKD) and compared its prognostic value in CKD3a versus CKD3b patients.

Methods. Patients (age $\geq 80$ years old) hospitalized with stage 3 CKD from 2007 to 2010 who were eligible for this prospective study underwent follow-up examinations in 2015. The examinations included measurements of anthropometric characteristics, blood pressure, plasma NT-proBNP, creatinine, and lipids. End-point events were all-cause death and major adverse cardiac events (MACEs). Results. A total of 168 patients (mean age $87.4 \pm 2.9$ years, range $80-99$ years) were included in the analysis (CKD3a, $n=117$; CKD3b, $n=51)$. The results showed that CKD3b was associated with lower hemoglobin levels, higher NT-proBNP levels and a higher rate of hypertension compared with CKD3a. After a median follow-up of 3.8 years (interquartile range 1.5-6.1 years), a higher NT-proBNP level was associated with a higher risk of all-cause death (hazard ratio HR 1.986, 95\% confidence interval $\mathrm{Cl} 1.276-2.819, p=0.028$ ) and MACEs (HR 2.872, 95\% Cl 1.241-6.644, $p=0.014$ ) after adjusting for age, sex, and traditional risk factors; however, a subgroup comparison showed that elevated NT-proBNP levels were associated with a higher risk of all-cause death (HR 2.350, 95\% Cl 1.906-6.091, $p=0.039$ ) and MACEs (HR 3.025, 95\% Cl 1.024-8.940, $p=$ 0.045) in CKD3a but not CKD3b. Conclusion. Levels of NT-proBNP increased with decreased renal function in very old patients with stage 3 CKD; therefore, NTproBNP is an independent predictor for allcause death and MACEs in these patients but has a greater prognostic value in CKD3a than in CKD3b.

Keywords

Prospective study · Aged - Chronic kidney disease $\cdot$ Risk factors $\cdot$ Cardiovascular disease

\section{Prognostischer Wert der NT-proBNP-Plasmakonzentration bei sehr alten Patienten mit moderater Niereninsuffizienz in China}

\begin{abstract}
Zusammenfassung
Hintergrund. Das „N-terminal pro-brain natriuretic peptide" (NT-proBNP) hat einen wichtigen prognostischen Wert für die chronische Niereninsuffizienz; jedoch wurde die Mehrzahl der Studien bei Patienten mit einer Nierenkrankheit im Endstadium durchgeführt. In dieser Studie beurteilten wir die prognostische Bedeutung von NT-proBNP bei sehr alten Patienten mit chronischer Niereninsuffizienz ("chronic kidney disease", CKD) Stadium 3 und verglichen dessen prognostischen Wert bei CKD3a vs. CKD3b. Methoden. Patienten (Alter $\geq 80$ Jahre), die von 2007 bis 2010 mit einer CKD Stadium 3 hospitalisiert wurden und die für diese prospektive Studie geeignet waren, unterzogen sich im Jahr 2015 Nachsorgeuntersuchungen. Die Untersuchungen umfassten Messungen anthropometrischer Werte, Blutdruck, NTproBNP-Plasmakonzentration, Kreatinin und Lipide. Endpunktereignisse waren Tod
\end{abstract}

jeglicher Ursache und schwere unerwünschte kardiale Ereignisse (MACEs).

Ergebnisse. Insgesamt 168 Patienten

(mittleres Alter: 87,4 $\pm 2,9$ Jahre, Range: $80-99$ Jahre) wurden in die Analyse eingeschlossen (CKD3a: $n=117$; CKD3b: $n=51$ ). Die Ergebnisse zeigten, dass CKD3b im Vergleich zu CKD3a mit geringeren Hämoglobinwerten, höheren NT-proBNP-Konzentrationen und einer höheren Hypertensionsrate assoziiert war. Nach einem medianen Follow-up von 3,8 Jahren (interquartile Spannweite: 1,5-6,1 Jahre) war eine höhere NT-proBNPKonzentration mit einem erhöhten Risiko für Tod jeglicher Ursache (Hazard-Ratio [HR] 1,986; 95\% Konfidenzintervall [CI] $1,276-2,819 ; p=0,028)$ und MACEs (HR 2,872; $95 \% \mathrm{Cl} 1,241-6,644 ; p=0,014)$ assoziiert, nachdem eine Anpassung für Alter, Geschlecht und traditionelle Risikofaktoren erfolgt war. Ein Subgruppenvergleich zeigte jedoch, dass eine erhöhte NT-proBNP-Konzentration in der CKD3a-Gruppe, jedoch nicht in der CKD3b-Gruppe, mit einem erhöhten Risiko für Tod jeglicher Ursache (HR 2,350, 95\% C $1,906-6,091 ; p=0,039$ ) und MACEs (HR 3,025, $95 \% \mathrm{Cl} 1,024-8,940 ; p=0,045)$ assoziiert war. Schlussfolgerung. Die NT-proBNP-Konzentrationen stiegen mit abnehmender Nierenfunktion bei sehr alten Patienten mit CKD Stadium 3. Daher ist NT-proBNP ein unabhängiger Prädiktor für Tod jeglicher Ursache und MACEs bei dieser Patientengruppe, wobei es bei CKD3a einen größeren prognostischen Wert hat als bei CKD3b.

\section{Schlüsselwörter}

Prospektive Studie · Alter - Chronische Niereninsuffizienz · Risikofaktoren · HerzKreislauf-Erkrankung infarction, coronary revascularization therapy, and newly diagnosed coronary artery disease by coronary artery imaging or stroke.

\section{Statistical analysis}

Continuous variables with a normal distribution are expressed as mean and standard deviation. Categorical variables are expressed as numbers and percentages. The NT-proBNP level is presented as a continuous variable (after natural logarithmic transformation). All analyses were performed at a median followup interval of 3.8 years (IQR 1.5-6.1). Continuous variables (demographic and clinical characteristics) were compared between groups by analysis of variance or Cuzick's nonparametric test for trend. Proportions were compared using the 


\section{Original contribution}

\begin{tabular}{|c|c|c|c|c|c|c|c|c|c|c|}
\hline \multirow[t]{2}{*}{ All-cause death } & \multirow[t]{2}{*}{ Model Cox } & \multirow[t]{2}{*}{$p$-value } & \multirow[t]{2}{*}{ HR } & \multicolumn{2}{|l|}{$95 \% \mathrm{Cl}$} & \multirow[t]{2}{*}{ MACEs } & \multirow[t]{2}{*}{$p$-value } & \multirow[t]{2}{*}{ HR } & \multicolumn{2}{|l|}{$95 \% \mathrm{Cl}$} \\
\hline & & & & Lower & Upper & & & & Lower & Upper \\
\hline \multicolumn{11}{|l|}{$n=168$} \\
\hline \multirow[t]{5}{*}{ CKD3 } & HR unadjusted & 0.023 & 1.482 & 1.195 & 2.207 & & 0.041 & 1.711 & 1.021 & 2.866 \\
\hline & Model 1 & 0.033 & 1.568 & 1.038 & 2.369 & & 0.043 & 1.699 & 1.016 & 2.843 \\
\hline & Model 2 & 0.033 & 1.727 & 1.046 & 2.852 & & 0.007 & 3.050 & 1.364 & 6.817 \\
\hline & Model 3 & 0.028 & 1.986 & 1.276 & 2.819 & & 0.014 & 2.872 & 1.241 & 6.644 \\
\hline & Model 4 & 0.350 & 1.348 & 0.720 & 2.524 & & 0.095 & 2.265 & 0.868 & 5.907 \\
\hline \multicolumn{11}{|l|}{$n=117$} \\
\hline \multirow[t]{5}{*}{ CKD3a } & HR unadjusted & 0.022 & 1.592 & 1.292 & 2.734 & & 0.047 & 1.892 & 0.996 & 3.595 \\
\hline & Model 1 & 0.035 & 1.618 & 1.336 & 2.797 & & 0.047 & 1.873 & 0.996 & 3.522 \\
\hline & Model 2 & 0.014 & 2.880 & 1.239 & 6.695 & & 0.005 & 4.417 & 1.573 & 12.405 \\
\hline & Model 3 & 0.039 & 2.350 & 1.906 & 6.091 & & 0.045 & 3.025 & 1.024 & 8.940 \\
\hline & Model 4 & 0.294 & 1.777 & 0.607 & 5.201 & & 0.334 & 2.036 & 0.481 & 8.615 \\
\hline \multicolumn{11}{|l|}{$n=51$} \\
\hline \multirow[t]{5}{*}{ CKD3b } & HR unadjusted & 0.354 & 1.326 & 0.730 & 2.411 & & 0.747 & 1.228 & 0.352 & 4.283 \\
\hline & Model 1 & 0.245 & 1.469 & 0.768 & 2.811 & & 0.567 & 1.485 & 0.384 & 5.749 \\
\hline & Model 2 & 0.603 & 1.322 & 0.461 & 3.788 & & 0.076 & 1.303 & 0.549 & 4.351 \\
\hline & Model 3 & 0.209 & 0.325 & 0.056 & 1.873 & & 0.263 & 2.457 & 1.055 & 4.181 \\
\hline & Model 4 & 0.675 & 1.562 & 0.194 & 12.611 & & 0.735 & 2.129 & 0.873 & 5.759 \\
\hline \multicolumn{11}{|c|}{$\begin{array}{l}\text { HR hazard ratio; CI confidence interval, CKD chronic kidney disease, MACEs major adverse cardiovascular events } \\
\text { Model } 1 \text { adjusted for age and sex } \\
\text { Model } 2 \text { adjusted for variables in model } 1 \text { plus the traditional cardiovascular risks CHD, hypertension, DM, AF, TC,TG, LDL-C, HDL-C, Hb, plasma albumin, BMI } \\
\text { Model } 3 \text { adjusted for variables in model } 2 \text { plus therapeutic drugs, such as antiplatelet drugs, statins, CCB, ACEI/ARB, beta-blocker } \\
\text { Model } 4 \text { adjusted for variables in model } 3 \text { plus LVEF, LAD and LVMI, MACEs }\end{array}$} \\
\hline
\end{tabular}

$\chi^{2}$-test and Fisher's exact test. The relationship between NT-proBNP levels and major end-points was evaluated using Cox proportional hazard regression model analysis. Model 1 was adjusted for age and sex, model 2 was adjusted for the variables in model 1 plus hypertension, DM, CHD, AF, tumor, lipid profile, hemoglobin $(\mathrm{Hb}), \mathrm{BMI}$, plasma albumin (ALB), mean systolic blood pressure, mean diastolic blood pressure, mean arterial pressure and pulse pressure, model 3 was adjusted for the variables in model 2 plus the use of major cardiovascular drugs, such as antiplatelet drugs, statins, renin-angiotensin system inhibitors, and beta-blockers and model 4 was adjusted for the variables in model 3 plus echocardiography parameters, such as LVEF, LAD, and LVMI. Differences in hazard ratios (HR) between patients with CKD3a and CKD3b were checked with interaction analysis. The cumulative incidences of mortality and MACEs were estimated using the Kaplan-Meier method. A receiver operating characteristic (ROC) curve was generated to evaluate the accuracy of NT-proBNP in the prediction of all-cause death and MACEs. All analyses were conducted using SPSS software for Windows, version 13.0 (SPSS, Chicago, IL); $p$ values < 0.05 were considered significant.

\section{Results}

\section{Patient characteristics}

A total of 168 patients (mean age $87.4 \pm$ 2.9 years, range 80-99) with moderate renal insufficiency were included in the analysis. There were 117 patients with CKD3a (mean age $87.4 \pm 2.7$ years) and 51 patients with CKD3b (mean age $87.7 \pm 3.4$ years). Demographic characteristics, cardiovascular risk factors, and related laboratory test results in each group are shown in - Table 1. The two groups did not differ significantly with respect to the prevalence of $\mathrm{CHD}$, $\mathrm{DM}, \mathrm{AF}$ or tumors or use of antiplatelet drugs, statins and renin-angiotensin system inhibitors. Patients with CKD3b had a higher prevalence of hypertension
(96.1\% vs. $76.9 \%, p=0.002)$, lower $\mathrm{Hb}$ levels $(116 \pm 15 \mathrm{~g} / \mathrm{l}$ vs. $122 \pm 13 \mathrm{~g} / \mathrm{l}, p<$ 0.001 ), and higher plasma NT-proBNP levels $(1227.7 \pm 1177.8 \mathrm{pg} / \mathrm{ml}$ vs. $785.4 \pm$ $752.0 \mathrm{pg} / \mathrm{ml}, p=0.021)$ compared with patients with CKD3a. In addition, the use of beta-blockers was significantly higher in patients with CKD3b $(51.0 \%$ vs. $34.2 \%, p=0.041)$.

\section{Prognostic value of NT-proBNP for all-cause death and MACEs in patients with stage 3 CKD}

During follow-up 101 of the 168 patients $(60.1 \%)$ died. Of these patients $16(15.8 \%)$ died of cardiac causes, 39 (38.6\%) died of infections and 26 (25.7\%) died of progressive cancer. In addition, 67 patients $(39.9 \%)$ suffered a MACE. Results of Cox proportional hazard model analysis showed that a higher NT-proBNP level was associated with a higher risk of all-cause death (HR 1.986, 95\% confidence interval CI 1.276-2.819, $p=0.028$ ) and MACEs (HR 2.872, 95\% CI $1.241-6.644, p=0.014)$ after ad- 

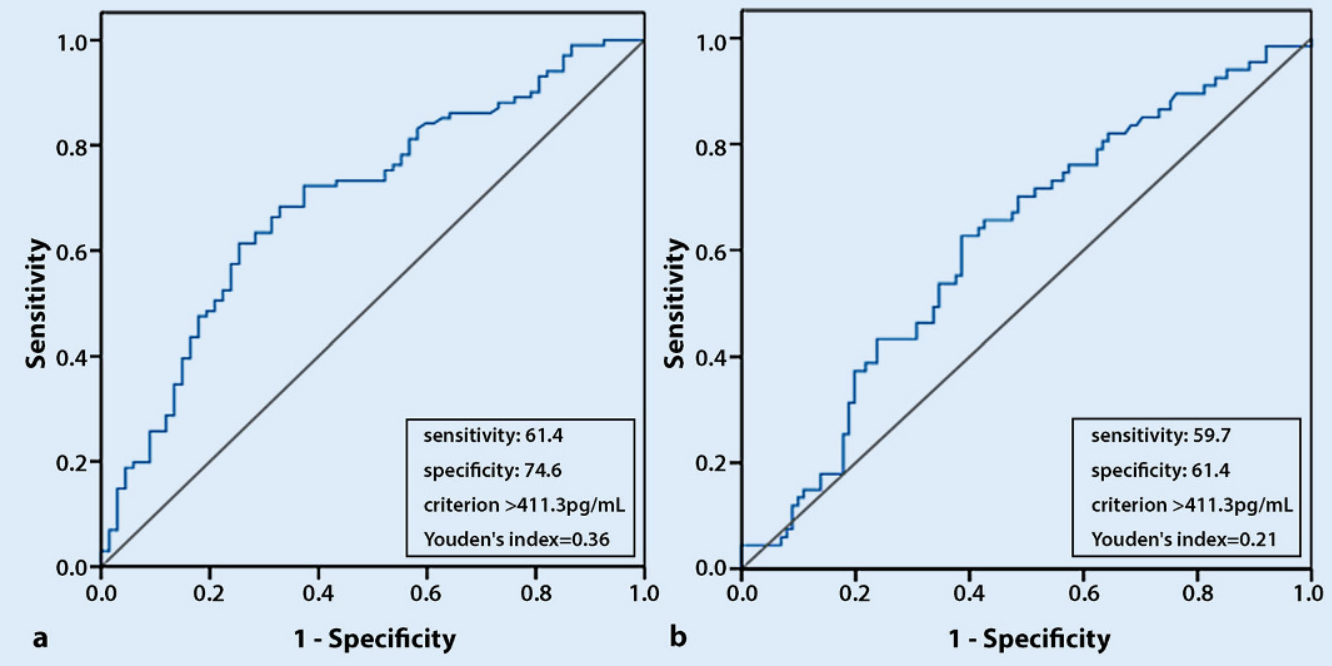

Fig. $1 \Delta$ a An ROC curve of NT-proBNP to predict all-cause death in patients with CKD3. AUC was $0.697(95 \% \mathrm{Cl} 0.616-0.778$, $p<0.001)$. b An ROC curve of NT-proBNP to predict MACEs in patients with CKD3. The AUC was 0.616 (95\% Cl 0.530-0.701, $p=0.011)$. ROC receiver operating characteristic, NT-proBNP N-terminal pro-brain natriuretic peptide, MACEs major adverse cardiovascular events, $A U C$ area under curves, $C l$ confidence interval. The black line is reference line. The blue line is ROC curve. The $X$-axes represents sensitivity, and the $Y$-axes represents specificity
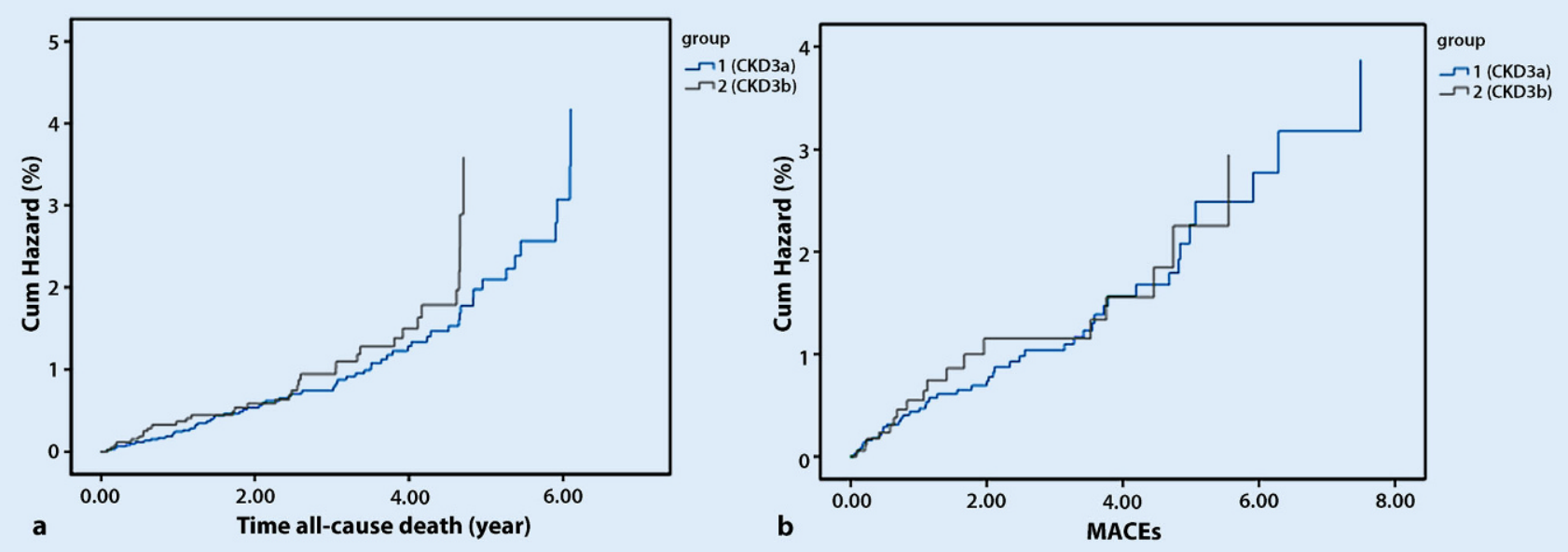

Fig. $2 \Delta$ a Kaplan-Meier cumulative hazard of all-cause death in CKD3a and CKD3b. Incidence of all-cause death in CKD3b (70.6\%) was significantly higher than in CKD3a (55.6\%, log-rank test $p=0.037)$. b Kaplan-Meier cumulative hazard of MACEs in CKD3a and CKD3b. Incidence of MACEs in CKD3b (37.3\%) was similar to CKD3a (41.0\%). Log-rank test $p=0.563$. The black line is reference line. The blue line is ROC curve. The $\mathrm{X}$-axes represents sensitivity, and the Y-axes represents specificity

justing for age, sex, BMI, comorbidities (CHD, hypertension, DM, and AF), lipid profiles, $\mathrm{Hb}, \mathrm{ALB}$, and major cardiovascular drugs (antiplatelet drugs, statins, calcium channel blockers, angiotensin-converting enzyme inhibitors, angiotensin receptor blockers, and betablockers); however, after further adjustment for LVEF, LAD, and LVMI (model 4), the NT-proBNP level was not associated with a higher risk of all-cause death and MACEs (• Table 2).

Results of the ROC analysis indicated that NT-proBNP had a reasonable accuracy for predicting all-cause death and MACEs. The area under the ROC curve was 0.697 (95\% CI 0.616-0.778, $p<0.001$ ) for all-cause death (• Fig. 1a). The cutoff NT-proBNP level for predicting allcause death was $411.3 \mathrm{pg} / \mathrm{ml}$ and had a maximum Youden index of 0.360 . For
MACEs, the area under the ROC curve was $0.616(95 \%$ CI $0.530-0.701, p=0.011)$ (- Fig. 1b), the cut-off NT-proBNP level for predicting MACEs was $411.3 \mathrm{pg} / \mathrm{ml}$ and the maximum Youden index was 0.241 . 

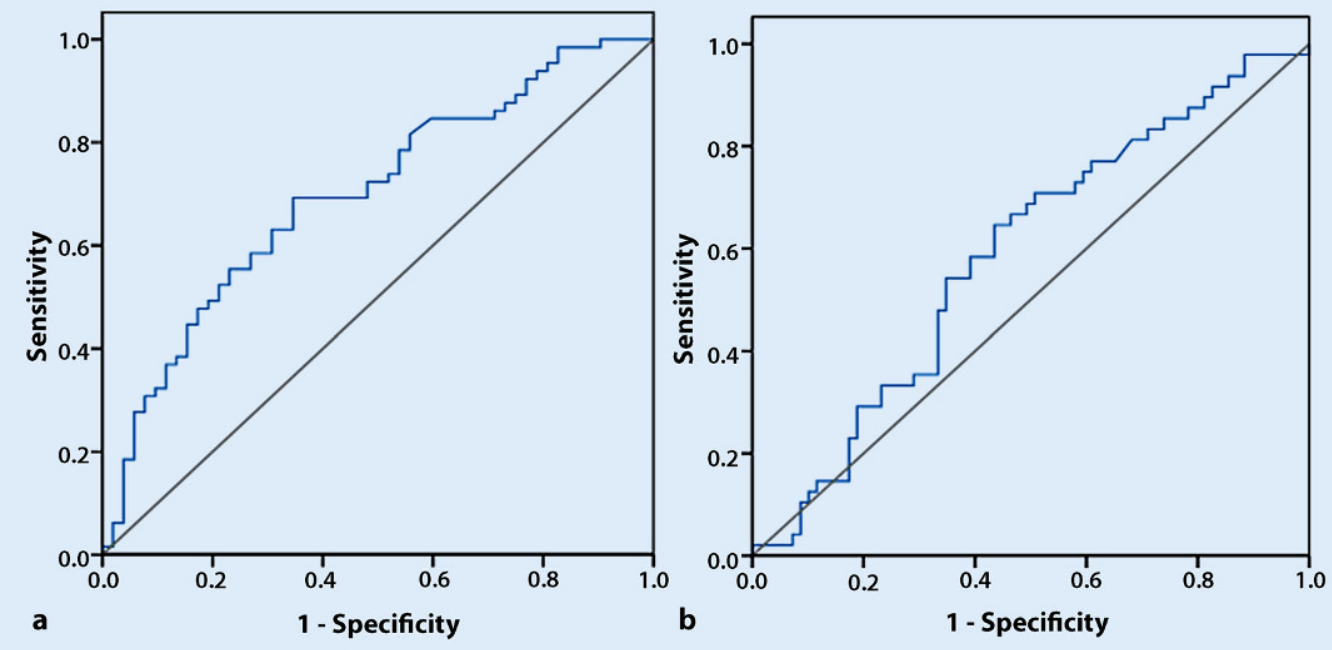

Fig. $3<$ a An ROC curve of NT-proBNP to predict all-cause death in patients with CKD3a. AUC was 0.699 (95\% Cl 0.604-0.794, $p<$ 0.001). b An ROC curve of NT-proBNP to predict MACEs in patients with CKD3a. AUC was 0.588 (95\% Cl 0.484-0.692, $p=$ $0.106)$. $R O C$ receiver operating characteristic, NT-proBNP N-terrninal pro-brain natriuretic peptide, MACEs major adverse cardiovascular events, AUC area under the curve, Cl confidence interval. Blue line: ROC curve; black line: reference line

\section{Prognostic value of NT-proBNP levels in CKD3a versus CKD3b}

Assessment of endpoints during the follow-up period showed that in the CKD3a group, 65 patients (55.6\%) died and 48 patients (41.0\%) underwent MACEs. In the CKD3b group, 36 patients (70.6\%) died and $19(37.3 \%)$ suffered MACEs. KaplanMeier survival analysis showed that survival was lower in the CKD3b group ( $p=$ 0.037), but the incidence of MACEs did not differ significantly between the two subgroups ( $p=0.563$ ) (• Fig. 2 ).

Results of Cox proportional hazard model analysis showed that in patients with CKD3a, a higher NT-proBNP level was associated with a higher risk of all-cause death (HR 2.350, 95\% CI 1.906-6.091, $p=0.039)$ and MACEs (HR 3.025, 95\% CI 1.024-8.940, $p=$ 0.045 ) after adjusting for multiple risk factors (model 3); however, in patients with CKD3b, NT-proBNP level had no predictive value for all-cause death and MACEs after adjusting for multiple risk factors (model 3) (- Table 2). By interaction analysis, the multiple adjusted HR values of NT-proBNP to predict allcause death ( 2.350 vs. $0.325, p=0.009)$ and MACEs (3.025 vs. $2.457, p=0.012$ ) were significantly higher in patients with CKD3a compared with CKD3b.

In patients with CKD3a the ROC analysis indicated that NT-proBNP had a reasonable accuracy for predicting all-cause death but not for predicting
MACEs. The area under the ROC curve was 0.699 (95\% CI $0.604-0.794, p<$ 0.001) for all-cause death (• Fig. 3a). The cut-off NT-proBNP level for predicting all-cause death was $288.9 \mathrm{pg} / \mathrm{ml}$ and had a maximum Youden index of 0.346. In patients with CKD3b, the area under the ROC curve was 0.588 (95\% CI $0.484-0.692, p=0.106)$ for MACEs (- Fig. 3b). The ROC analysis indicated that NT-proBNP had no value for predicting all-cause death and MACEs in patients with CKD3b.

\section{Discussion}

The main findings of this study include the following: first, in very old patients with stage $3 \mathrm{CKD}$, the prevalence of hypertension, beta-blocker use, and NTproBNP levels increased with the deterioration of renal function, but $\mathrm{Hb}$ levels decreased. Secondly, baseline NT-proBNP level was an independent predictive factor for all-cause death and MACEs in patients with stage $3 \mathrm{CKD}$, but echocardiography parameters weakened the predictive value of NT-proBNP. In particular, the risk of all-cause death and MACEs was elevated in patients with NT-proBNP levels $\geq 411.3 \mathrm{pg} / \mathrm{ml}$ in our study, suggesting this value as the cut-off NT-proBNP level for prediction of all-cause death and MACEs in old patients with stage 3 CKD. Thirdly, the risk of all-cause death was significantly higher in patients with CKD3b than in patients with CKD3a, and the prognostic value of NT-proBNP was better in CKD3a than in CKD3b.

The CKD is increasingly being recognized as a global public health problem substantially contributing to adverse clinical outcomes. Advanced age is a well-known risk factor for CKD [1], which is often associated with anemia, hypertension, and proteinuria, factors that increase the risk of cardiovascular disease and all-cause death. The increased NT-proBNP level and prevalence of hypertension, and decreased $\mathrm{Hb}$ level with the deterioration of renal function observed in our study, are consistent with the findings of previous studies [3]. Zhang et al. [2] found that the prevalence of CKD in the Chinese population was $10.8 \%$, which is lower than the prevalences of $7.7 \%$ in the USA and $4.2 \%$ in Norway, and the prevalence of CKD3 was $1.6 \%[3,13]$. Lin et al. [14] found that stage $3 \mathrm{CKD}$ was more common in older patients than in younger patients (33.5\% vs. $4.1 \%)$ in Asia. Quality of life is better in stage $3 \mathrm{CKD}$ than in ESRD and disease progression and adverse outcomes, such as kidney failure, cardiovascular disease, and premature death can be prevented or delayed when treatment is initiated in the early stages of disease [15]; therefore, patients with stage 3 CKD should receive comprehensive treatment. The results of two metaanalyses showed that the risk of adverse kidney outcomes and all-cause mortality is substantially higher in patients with 
eGFR values of $30-44 \mathrm{ml} / \mathrm{min} / 1.73 \mathrm{~m}^{2}$ compared to those with eGFR values of $45-60 \mathrm{ml} / \mathrm{min} / 1.73 \mathrm{~m}^{2}[16,17]$. This suggests that it may be appropriate to subdivide stage $3 \mathrm{CKD}$ into CKD3a and $\mathrm{CKD} 3 \mathrm{~b}$ in the updated guidelines [10].

Brain natriuretic peptide (BNP) is produced as a prehormone (proBNP) by cardiac myocytes in response to ventricular wall stretching and tension [18]. Compared with BNP, NT-proBNP has a longer half-life and is more stable in vitro, making it easier to detect. Previous studies have shown that NT-proBNP is a significant predictor of cardiovascular disease and all-cause death in various populations [19, 20]; however, these studies were performed mainly in patients with ESRD on hemodialysis [5, 6]. The present study is the first to report that the NT-proBNP level is an independent predictive factor for all-cause death and MACEs in very old ( $\geq 80$ years old) patients with stage 3 CKD. These results indicate that monitoring NT-proBNP level is helpful for assessing the risk of all-cause death and MACEs, correcting risk factors, and delaying the deterioration of renal function in this patient population.

There are several possible explanations for the association between elevated NTproBNP level and risk of all-cause death and MACEs in our study. Firstly, an elevated plasma NT-proBNP level is associated with a variety of factors including old age, anemia, and combined hypertension and coronary heart disease, which are the risk factors for all-cause death and MACEs [21]. Secondly, increased plasma NT-proBNP level may indicate more advanced renal dysfunction, and deterioration of renal function is associated with all-cause death and MACEs [22]. Thirdly, elevated levels of plasma NTproBNP denote impaired cardiac function, including latent structural heart diseases, cardiac volume overload, and myocardial damage [23]. In this study, NTproBNP was not an independent predictor of all-cause death and MACEs after adjusting for echocardiography parameters (LVEF, LAD, and LVMI). Both abnormal echocardiography parameters and elevated plasma NT-proBNP level denote impaired cardiac structure and function, but no published studies have compared the prognostic value of NTproBNP and echocardiography parameters.

The prognosis based on the NTproBNP level has not been thoroughly studied in CKD patients, and there is no standard cut-off value for NT-proBNP to predict adverse events in this population. Fu et al. [24] reported that NTproBNP predicted death with a cut-off value of $369.5 \mathrm{pg} / \mathrm{ml}$ in non-CKD patients and a cut-off value of $2584.1 \mathrm{pg} / \mathrm{ml}$ in CKD patients. In the present study, the risks of all-cause death and MACEs were particularly increased in patients with NT-proBNP levels $\geq 411.3 \mathrm{pg} / \mathrm{ml}$, suggesting this value as an appropriate cut-off NT-proBNP level for prediction of all-cause death and MACEs in very old patients with stage $3 \mathrm{CKD}$. The cutoff value for predicting all-cause death suggested by $\mathrm{Fu}$ et al. was significantly higher than that of the present study (2584.1 pg/ml vs. $411.3 \mathrm{pg} / \mathrm{ml}$ ). Possible explanations for this discrepancy include differences in the percentages of patients with heart failure, AF, and anemia and levels of NT-proBNP, which were higher in the study by Fu et al. [24]. In addition, the study population of $\mathrm{Fu}$ et al. consisted of patients with coronary artery disease, whereas patients with coronary artery disease accounted for $79.1 \%$ of the patients in our study. It is difficult to determine an explicit cut-off value for predicting all-cause death and MACEs in patients with $\mathrm{CKD}$ because the range of plasma NT-proBNP values is wide, especially in the old; therefore, further study is needed to determine the best cut-off value for plasma NT-proBNP in very old patients with stage 3 CKD.

Patients with CKD are at increased risk of mortality, cardiovascular disease, and less commonly, progression to ESRD [25] and these risks are increased with deterioration of renal function [26]. In the present study, the mortality rate was significantly higher in patients with CKD3b than in those with CKD3a (70.6\% vs. $55.6 \%, p=0.037$ ) during follow-up, but the incidence of MACEs did not significantly differ ( $41.0 \%$ vs. $37.3 \%, p=0.563$ ). This discrepancy may be due to death occurring before the occurrence of MACEs in patients with $\mathrm{CKD} 3 \mathrm{~b}$. In addition, the prognostic value of NT-proBNP for predicting mortality and MACEs was better in CKD3a than in CKD3b. The reason for this discrepancy is not clear but may be associated with the small sample size in this study. There is a different mode of clearance of the NT-proBNP in patient with $\mathrm{CKD} 3 \mathrm{~b}$, and many other factors that have not been discussed in this study affect the prognosis of patients with CKD3b. Further studies are needed to compare the prognostic value of NTproBNP in CKD3a versus CKD3b.

Several limitations should be considered when interpreting our results. Firstly, the study population was relatively small; therefore, large studies are needed to confirm our results. Secondly, in this patient population, numerous factors can affect plasma NT-proBNP levels and patient outcomes. Although the results were adjusted for multiple covariates that may be associated with circulating NT-proBNP levels and outcomes, there is a possibility of residual confounding factors. Thirdly, in this study, an inclusion criterion was eGFR < $60 \mathrm{ml} / \mathrm{min} / 1.73 \mathrm{~m}^{2}$ calculated by the MDRD (Modification of Diet in Renal Disease) formula, which may be less representative of actual eGFR in very old patients because of reduced muscle mass [27].

\section{Conclusion}

The NT-proBNP level is a strong and independent prognostic factor for all-cause death and MACEs in very old patients with CKD stage 3. Furthermore, patients with a NT-proBNP level $\geq 411.3 \mathrm{pg} / \mathrm{ml}$ have a significantly higher risk of allcause death and MACEs, suggesting the potential usefulness of this NT-proBNP level as a cut-off value for predicting adverse events in this population. In addition, the prognostic value of NT-proBNP was better in CKD3a than in CKD3b. 


\section{Corresponding address}

\section{H. Liu}

Department of Geriatric Cardiology, Chinese

PLA General Hospital

28 Fuxing Road, 100853 Beijing, Haidian

District, China

hongwei_liu301@sohu.com

Acknowledgements. The authors thank all participants for their involvement in the study.

\section{Compliance with ethical guidelines}

Conflict of interests. P. Gao, Q. Zhu, S. Bian, H. Liu and $\mathrm{H}$. Xie declare that they have no competing interests.

Open Access This article is distributed under the terms of the Creative Commons Attribution 4.0 International License (http://creativecommons.org/licenses/by/ 4.0/), which permits unrestricted use, distribution, and reproduction in any medium, provided you give appropriate credit to the original author(s) and the source, provide a link to the Creative Commons license, and indicate if changes were made.

\section{References}

1. Chudek J, Wieczorowska-Tobis K, Zejda J et al (2014) The prevalence of chronic kidney disease and its relation to socioeconomic conditions in an elderly Polish population: results from the national population-based study PolSenior. Nephrol Dial Transplant 29(5):1073-1082

2. Zhang L, Wang F, Wang L, Wang W, Liu B, Liu $J$ (2012) Prevalence of chronic kidney disease in China: a cross-sectional survey. Lancet 379(9818):815-822

3. Coresh J, Selvin E, Stevens LA, Manzi J, Kusek JW, Eggers P (2007) Prevalence of chronic kidney disease in the United States. J Am Med Assoc 298(17):2038-2047

4. Nadir MA, Witham MD, Szwejkowski BR, Struthers AD (2011) Meta-analysis of B-type natriuretic peptide's ability to identify stress induced myocardial ischemia. Am J Cardiol 107(5):662-667

5. Locatelli F, Hannedouche T, Martin-Malo A, Jacobson SH, Vanholder R, Ronco C (2013) The relationship of NT-proBNP and dialysis parameters with outcome of incident haemodialysis patients: results from the membrane permeability outcome study. Blood Purif 35(1-3):216-223

6. Oh HJ, Lee MJ, Kwon YE, Park KS, Park JT, Han SH (2015) Which biomarker is the best for predicting mortality in incident peritoneal dialysis patients: NT-proBNP, cardiac TnT, or hsCRP? Medicine (Baltimore) 94(44):e1636

7. Manjunath G, Tighiouart H, Ibrahim H, MacLeod B, SalemDN, Griffith JL (2003) Level of kidney function as a risk factor for atherosclerotic cardiovascular outcomes in the community. J Am Coll Cardiol 41(1):47-55

8. Lang RM, Bierig M, Devereux RB, Flachskampf FA, Foster E, Pellikka PA (2005) Recommendations for chamber quantification: a report from the American Society of Echocardiography's Guidelines and Standards Committee and the Chamber Quantification Writing Group, developed in conjunction with the European Association of Echocardiography, a branch of the European Society of Cardiology. J Am Soc Echocardiogr 18(12):1440-1463

9. Ma YC, Zuo L, Chen JH, Luo Q, Yu XQ, Li Y (2006) Modified glomerular filtration rate estimating equation for Chinese patients with chronic kidney disease. J Am Soc Nephrol 17(10):2937-2944

10. Kidney Disease: Improving Global Outcomes(KDIGO) CKD Work Group (2013) KIDGO 2012 clinical practice guideline for the evaluation and management of chronic kidney disease. Kidney Int Suppl 3(1):1-150

11. Hu Y, Wu XL, Hu ZH (1999) Research on the formula of human body surface area in China. J Physiol 51(1):45-48

12. Hu J, Wallace DC, Jones E, Liu H (2009) Cardiometabolic health of Chinese older adults with diabetes living in Beijing, China. Public Health Nurs 26(6):500-511

13. Hallan SI, Coresh J, Astor BC, Asberg A, Powe NR, Romundstad S (2006) International comparison of the relationship or chronic kidney disease prevalence and ESRD risk. J Am Soc Nephrol 17(8):2275-2284

14. Lin MY, Chiu YW, Lee CH, Yu HY, Chen HC, Wu MT (2013) Factors associated with CKD in the elderly and nonelderly population. Clin J Am Soc Nephrol 8(1):33-40

15. James MT, Hemmelgarn BR, Tonelli M (2010) Early recognition and prevention of chronic kidney disease. Lancet 375(9722):1296-1309

16. Gansevoort RT, Matsushita K, van der Velde M, Astor BC, Woodward M, Levey AS (2011) Lower estimated GFR and higher albuminuria are associated with adverse kidney outcomes. A collaborative meta-analysis of general and highrisk population cohorts. Kidney Int 80(1):93-104

17. Van der Velde $M$, Matsushita K, Coresh J, Astor BC, Woodward M, Levey A (2011) Lower estimated glomerular filtration rate and higher albuminuria are associated with all-cause and cardiovascular mortality. A collaborative metaanalysis of high-risk population cohorts. Kidney Int 79(12):1341-1352

18. Wang AY, Lai KN (2008) Use of cardiac biomarkers in end-stage renal disease. J Am Soc Nephrol 19(9):1643-1652

19. Zhu Q, Xiao W, Bai Y, Ye P, Luo L, Gao P (2016) The prognostic value of the plasma $\mathrm{N}$-terminal probrain natriuretic peptide level on all-cause death and major cardiovascular events in a communitybased population. Clin Interv Aging 11:245-253

20. Laukkanen JA, Kurl S, la-Kopsala M, Vuolteenaho O, Ruskoaho H, Nyyssönen K (2006) Plasma $\mathrm{N}$-terminal fragments of natriuretic propeptides predict the risk of cardiovascular events and mortality in middle-aged men. Eur Heart J 27(10):1230-1237

21. Couser WG, Remuzzi G, Mendis S, Tonelli M (2011) The contribution of chronic kidney disease to the global burden of major noncommunicable diseases. Kidney Int 80(12):1258-1270

22. Hemmelgarn BR, Manns BJ, Lloyd A, James MT, Klarenbach S, Quinn RR (2010) Relation between kidney function, proteinuria, and adverse outcomes. JAMA 303(5):423-429

23. Sakuma M, Nakamura M, Tanaka F, Onoda T, Itai K Tanno K (2010) Plasma B-type natriuretic peptide level and cardiovascular events in chronic kidney disease in a community-based population. Circ J 74(4):792-797

24. Fu S, Luo L, Ye P, Yi S, Liu Y, Zhu B (2013) The ability of NT-proBNP to detect chronic heart failure and predict all-cause mortality is higher in elderly Chinese coronary artery disease patients with chronic kidney disease. Clin Interv Aging 8:409-417

25. Tangri N, Stevens LA, Griffith J, Tighiouart $H_{\text {, }}$ Djurdjev O, Naimark D (2011) A predictive model for progression of chronic kidney disease to kidney failure. JAMA 305(15):1553-1559

26. Cichocka-Radwan A, Ciurus T, Lelonek M (2014) The impact of chronickidney disease on the annual prognosis in patients 80 + years old suffering from chronic heart failure. Kardiochir Torakochir Pol 11(3):294-300

27. Lamb EJ, O'Riordan SE, Webb MC, Newman DJ (2003) Serum cystatin C may be a better marker of renal impairment than creatinine. J Am Geriatr Soc 51(11):1674-1675 